\title{
Effect of organo-modified montmorillonite on poly(butylene succinate)/poly(butylene adipate-co-terephthalate) nanocomposites
}

\author{
B. W. Chieng, N. A. Ibrahim*, W. M. Z. Wan Yunus \\ Chemistry Department, Faculty of Science, Universiti Putra Malaysia, 43400 UPM Serdang, Selangor, Malaysia
}

Received 6 March 2010; accepted in revised form 24 April 2010

\begin{abstract}
The composite material based on poly(butylene succinate) (PBS), poly(butylene adipate-co-terephthalate) (PBAT) and organo-modified montmorillonite (OMMT) were prepared by melt blending technique and characterized. Sodium montmorillonite (Na-MMT) was successfully modified by octadecylammonium (ODA) and dimethyldioctadecylammonium (DDOA) salts to become OMMT through cation exchange technique which is shown by the increase of basal spacing of clay by XRD. The addition of the OMMT to the PBS/PBAT blends produced nanocomposites which is proved by XRD and TEM. Tensile tests showed increase in tensile strength and modulus which is attributed to the existence of strong interactions between PBS/PBAT and clay, particularly with OMMT. Highest tensile strength of nanocomposite was observed at $1 \mathrm{wt} \%$ of OMMT incorporated. TGA study showed that the thermal stability of the blend increased after the addition of clays. SEM micrographs of the fracture surfaces show that the morphology of the blend becomes homogeneous and smoother with presence of OMMT.
\end{abstract}

Keywords: nanocomposites, biodegradable, OMMT

\section{Introduction}

Nanocomposites based on biodegradable polyester and layered silicate have been extensively investigated because of their potential applications in the fields related to environmental protection. Biodegradable polymers are degradable polymers in which the degradation results from the action of naturally occurring microorganism such as bacteria, fungi and algae. Although biodegradable polymers have started making inroads into commercial applications, there is still lot of potential in the improvement of their properties for commercial large scale application.

Montmorillonite is one of the commercial layered silicates and has been widely used as reinforcing filler in the preparation of nanocomposites. However, the hydrophilic nature of montmorillonite limits its compatibility with organophilic polymers. Thus, chemical modification has been developed to make montmorillonite compatible with organophilic polymer. This can be readily achieved by modifying the montmorillonite with alkylammonium salts to form organo-montmorillonite (OMMT).

Poly(butylene succinate) (PBS) is a biodegradable aliphatic thermoplastic which synthesized by polycondensation of 1,4-butanediol with succinic acid. PBS possesses many desirable properties including biodegradability, melt processability, and thermal and chemical resistance. It can be processed in the field of textiles into melt-blown, multifilament, monofilament, flat and split yarn [1]. However, other properties such as gas barrier properties, melt viscosity for further processing and so on, are frequently insufficient for various end-use applica-

*Corresponding author, e-mail: norazowa@science.upm.edu.my (C) BME-PT 
tions [2]. Poly(butylene adipate-co-terephthalate) PBAT, trade name ECOFLEX ${ }^{\circledR}$ is an aliphatic/aromatic copolyester based on the monomers 1,4butanediol, adipic acid and terephthalic acid. It is fully biodegradable polymer and is resistant to water. Typical applications are packaging films, agricultural films and compose bags.

Blending two or more polymers is an economic technique for producing new polymer materials at low cost and desirable properties combination for specific end use. They can be developed much more quickly than new polymers and require much less capital investment. However, thermodynamic immiscibility of polymers had limited the use of polymer blends in industry. These immiscible blends are characterized by a two phase morphology, narrow interphase, poor physical and chemical interactions across the phase boundaries, and poor mechanical properties. Many studies have focused on improving the compatibility between polymer components, either by adding third component, or by inducing a chemical reaction which leads to the modification of polymer interface [3]. To improve the properties of PBS, many researchers introduce clays to the PBS system [4-6]. Researchers also tried to improve the properties of PBS by blending with other polymers [7]. Jacob et al. [8] have studied the compatibility between PBS and PBAT. They revealed that this blend is immiscible but only one $T_{g}$ was observed due to the close proximity of individual $T_{g}$ 's of both PBS and PBAT. Other reports have shown that OMMT can act as compatibilizer for immiscible polymer blends [9-15] which exhibit remarkable improvement in their properties compared to the pristine polymer or the conventional composite $[16,17]$. The interlayer cations between the silicate layers such as $\mathrm{Na}^{+}$are exchanged with organic cations to increase the organonophilicity of the clay layers. This lowers the interfacial energy and improves wetting by the polymer matrix [16].

In this study, the OMMT was used as compatibilizer to improve the miscibility of the PBS/PBAT blends. The PBS/PBAT composites were prepared by the melt blending technique and the effect of OMMT on physical, mechanical and thermal properties was investigated. The compatibility between the PBS and PBAT was studied by examining the fracture surface of the tensile test specimens under SEM.

\section{Experimental}

\subsection{Materials}

Poly(butylene succinate) PBS, was supplied by Showa Highpolymer Co. Ltd. (Japan) under tradename 'BIONOLLE', grade \#1020. The PBS pellets were dried in an oven at $60^{\circ} \mathrm{C}$ for 24 hours before processing. The poly(butylene adipate-co-terephthalate) PBAT, trade name ECOFLEX ${ }^{\circledR}$ F BX 7011 was supplied by BASF. PBAT was supplied in pellet form and used as received. Properties of BIONOLLE and ECOFLEX are summarized in Table 1. Na-MMT (Kunipia F) with cation exchange capacity of $119 \mathrm{meq} / 100 \mathrm{~g}$ was obtained from Kunimine Ind. Co. Japan and used as received. Octadecylamine and dimethyldioctadecylammonium bromide was purchased from Acros Organics and used as an organic modifier of montmorillonite.

Table 1. Properties of BIONOLLE and ECOFLEX

\begin{tabular}{|l|c|c|}
\hline \multicolumn{1}{|c|}{ Properties } & BIONOLLE & ECOFLEX \\
\hline Melting point & $116^{\circ} \mathrm{C}$ & $110^{\circ} \mathrm{C}$ \\
\hline Glass transition & $-31^{\circ} \mathrm{C}$ & $-29^{\circ} \mathrm{C}$ \\
\hline $\begin{array}{l}\text { Melt mass-flow rate } \\
\left(190^{\circ} \mathrm{C} / 2.16 \mathrm{~kg}\right)\end{array}$ & $20-29 \mathrm{~g} / 10 \mathrm{~min}$ & $2.7-4.9 \mathrm{~g} / 10 \mathrm{~min}$ \\
\hline Molecular weight $\left(M_{w}\right)$ & $\sim 40000$ & 40000 \\
\hline Crystallinity & $30-50 \%$ & $\sim 20 \%$ \\
\hline
\end{tabular}

\subsection{Preparation of OMMT}

The organo-modified montmorillonite (OMMT) was prepared according to the published method with slight modification [18]. The octadecylammonium-montmorillonite (ODA-MMT) was prepared by adding a dispersed $20.00 \mathrm{~g}$ of sodium montmorillonite in $800 \mathrm{ml}$ of distilled water at $80^{\circ} \mathrm{C}$ into a solution of $13.476 \mathrm{~g}$ octadecylamine and $4.81 \mathrm{ml}$ concentrated hydrochloric acid in $200 \mathrm{ml}$ hot distilled water. The resultant suspension was vigorously stirred for 1 hour. The precipitate was repeatedly filtered and washed with hot distilled water until no chloride ion was detected with $0.1 \mathrm{~N}$ $\mathrm{AgNO}_{3}$ solution. It was then dried at $60^{\circ} \mathrm{C}$ for 24 hours. The OMMT was ground with a mortar and sieved into particles of size less than $100 \mu \mathrm{m}$ which will then used for the preparation of nanocomposites. Similar procedure was adopted to prepare dimethyldioctadecylammonium-montmorillonite (DDOA-MMT) with DDOA as intercalation agent. 


\subsection{Preparation of poly(butylene succinate) (PBS)/poly(butylene adipate-co-terephthalate) (PBAT)/clay nanocomposites}

Nanocomposites containing a thermoplastic blend and clay were produced by melt compounding. The blend composition was kept constant (PBS $70 \mathrm{wt} \%$ + PBAT $30 \mathrm{wt} \%$ ), whereas the clay content was varied between 0 and $7 \mathrm{wt} \%$. PBS, PBAT and clay were manually premixed in a container and fed into Brabender at $130^{\circ} \mathrm{C}$ and rotor speed of $50 \mathrm{rpm}$. The residence time was maintained at 10 minutes for all the preparation. The products were then compression molded into sheets of $1 \mathrm{~mm}$ thickness by an electrically heated hydraulic press with a force of $1500 \mathrm{kN}$ at $125^{\circ} \mathrm{C}$ for 10 minutes. The sample sheets were then use for further characterization.

\subsection{X-ray diffraction (XRD)}

$\mathrm{X}$-ray diffraction measurement was carried out by using a Shimadzu XRD 600 X-ray diffractometer with $\mathrm{CuK}_{\alpha}$ radiation $(\lambda=1.542 \AA)$ operated at $30 \mathrm{kV}$ and $30 \mathrm{~mA}$. Data were collected within the range of scattering angles $(2 \theta)$ of 2 to $10^{\circ}$ at the rate of $2 \% \mathrm{~min}$. The basal spacing of the clay was derived from the peak position ( $d_{001}$ reflection) in the XRD diffractogram according to the Bragg equation $(\lambda=2 d \sin \theta)$.

\subsection{Fourier Transform Infrared (FTIR)}

Fourier transform infrared spectra were recorded using a Spectrum BX Perkin Elmer using KBR disk method in the range of frequency 280 to $4000 \mathrm{~cm}^{-1}$ at $25^{\circ} \mathrm{C}$. FTIR spectrum was recorded using transmission method. For each spectrum, 128 consecutive scans with $4 \mathrm{~cm}^{-1}$ resolution were averaged.

\subsection{Tensile properties}

Tensile properties test were carried out by using Instron 4302 series IX. The samples were cut into the dumbbell shape follow the ASTM D638 (type V) standard. Average thickness and average width of the gauge section of each specimen were calculated using three measurements of the thickness and width respectively. A digital micrometer, Mitutoyo (Japan) with an accuracy of $0.001 \mathrm{~mm}$ was used in the measurements. Load of $1.0 \mathrm{kN}$ was applied at constant crosshead speed of $10 \mathrm{~mm} / \mathrm{min}$ at room temperature. Tensile strength and tensile moduli were evaluated from the stress-strain data. Seven specimens were tested and the average of the values was taken.

\subsection{Thermogravimetric Analysis (TGA)}

Thermogravimetric analysis was performed using a Perkin Elmer TGA7. The weight of the samples used was about $10.0 \mathrm{mg}$ and were heated from 35 to $600^{\circ} \mathrm{C}$ at the heating rate of $10^{\circ} \mathrm{C} / \mathrm{min}$. The analysis was carried out in nitrogen atmosphere with nitrogen flow rate of $20 \mathrm{ml} / \mathrm{min}$. The weight loss of samples were recorded and plotted as the function of temperature.

\subsection{Scanning Electron Microscopy (SEM)}

Scanning Electron Microscopy was done using JEOL scanning microscope JSM-6400, Japan operated at $20 \mathrm{kV}$. Fracture surfaces were obtained from plain strain fracture tensile tested specimens. The fracture surfaces were sputter coated with gold. A selective dissolution of polyester in dimethylformamide (DMF) was used to distinguish phases. The sample was held in DMF for 10 minutes, removed and dried. The surface of the blend was examined for changes in its phase morphology.

\subsection{Transmission Electron Microscopy} (TEM)

Transmission Electron Microscopy image were obtained using a Hitachi H-700 TEM operated at an accelerating voltage of $100 \mathrm{kV}$ to observe the nanoscale structures of the composites. All samples were ultrathin-sectioned using a microtome equipped with a diamond knife. The samples were collected in a trough filled with water and placed on a 200 mesh copper grid.

\section{Results and discussion}

\subsection{Characterization of OMMT}

\subsubsection{Fourier Transform Infrared (FTIR)}

FTIR spectra of Na-MMT and OMMT (ODA-MMT and DDOA-MMT) are illustrated in Figure 1. For the unmodified montmorillonite, Na-MMT, the presence of broad band at $3400 \mathrm{~cm}^{-1}$ indicates the 


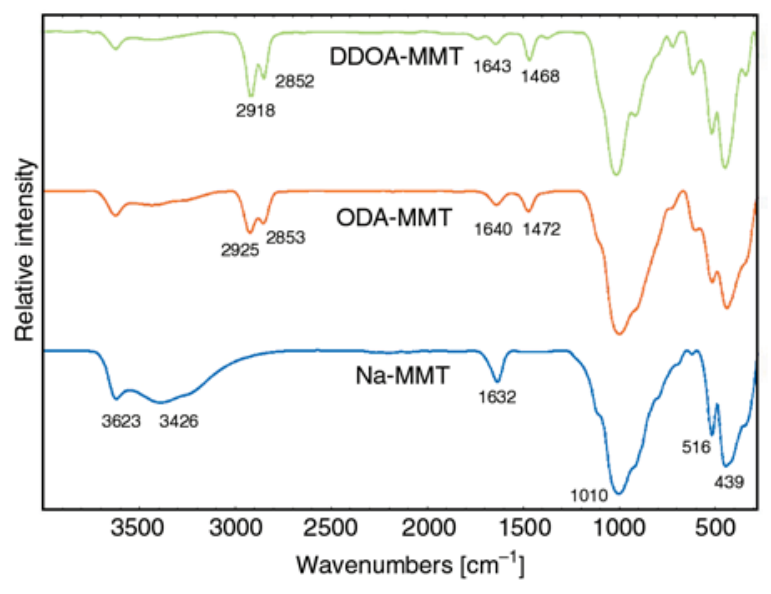

Figure 1. FTIR spectra of Na-MMT, ODA-MMT and DDOA-MMT

presence of the free water molecules vibration. This less intense band is ascribed to water hydrogen bonded to other water molecules within the interlayer of the montmorillonite. These molecules are involved with the structure of the hydration sphere of the $\mathrm{Na}^{+}$cation within the montmorillonite interlayer. It also shows that the hydrophilic nature of Na-MMT and water present in the Na-MMT. The infrared spectrum of Na-MMT exhibited four unique characteristic peaks which correspond to the $\mathrm{O}-\mathrm{H}$ stretching $\left(3623 \mathrm{~cm}^{-1}\right), \mathrm{Si}-\mathrm{O}$ stretching $\left(1010 \mathrm{~cm}^{-1}\right), \mathrm{Al}-\mathrm{O}$ stretching $\left(516 \mathrm{~cm}^{-1}\right)$ and $\mathrm{Si}-\mathrm{O}$ bending $\left(439 \mathrm{~cm}^{-1}\right)$. The OMMT presents three new peaks in the FTIR spectrum compared to NaMMT. The Bands around 2918 and $2852 \mathrm{~cm}^{-1}$ are attributed to the $\mathrm{C}-\mathrm{H}$ asymmetric and symmetric stretching vibrations of surfactant, respectively. The band around $1468 \mathrm{~cm}^{-1}$ is assigned to the $\mathrm{CH}_{2}$ methylene (scissoring) vibration. The existence of these three new peaks in OMMT confirm the intercalation of alkylammonium ion in the interlayer spaces of montmorillonite [19]. This can further be confirmed with XRD observation.

On the other hand, the OMMT also become more organophilic as shown by the reduction in intensity of free $\mathrm{O}-\mathrm{H}$ stretching peak. Furthermore, the $\mathrm{H}-\mathrm{O}-\mathrm{H}$ bending vibration of the water molecules is sensitive to the clay surface property transformation from hydrophilic to organophilic. The shifting of the $\mathrm{H}-\mathrm{O}-\mathrm{H}$ bending $\left(1632 \mathrm{~cm}^{-1}\right)$ to a higher frequency $\left(\sim 1640 \mathrm{~cm}^{-1}\right)$, indicationg that $\mathrm{H}_{2} \mathrm{O}$ is less hydrogen bonded and total sorbed water content decreases. Hydrophobic cations in organoclay will weaken the hydrogen bonding of the water. For the weaker hydrogen bond, lower energy is required for $\mathrm{H}-\mathrm{O}-\mathrm{H}$ bending vibration and thus a higher frequency of the $\mathrm{H}-\mathrm{O}-\mathrm{H}$ can be observed [20]. IR spectrum of OMMT keeps all the characteristic absorption bands of the host structure Na-MMT, it indicates that surfactants are intercalated into the silicate layer of Na-MMT. Therefore the clay was successfully modified to become OMMT.

\subsubsection{X-ray diffraction analysis (XRD)}

The changes of basal spacing of the resulted materials can reflect the intercalation of surfactant cation into montmorillonite interlayer spaces [21]. The natural montmorillonite, Na-MMT has $1.24 \mathrm{~nm}$ of basal spacing at $2 \theta=7.12^{\circ}$ before it was modified with different surfactants. This basal spacing value is similar to the value obtained from the XRD measurement of previous work [22]. The values of $2 \theta$ and basal spacing of clays are summarized in Table 2. The XRD patterns for the clays are illustrated in Figure 2. After being modified by the surfactant ODA and DDOA, the basal spacing of the clay increase from 1.24 to 2.83 and $3.20 \mathrm{~nm}$ respectively. These indicated that the exchange cation is intercalated into the galleries of silicate layers after it is exchanged with the sodium ion. Thus montmorillonite is successfully modified by the surfactant and OMMT is formed.

Table 2. Basal spacing of Na-MMT, ODA-MMT and DDOA-MMT

\begin{tabular}{|l|l|c|c|}
\hline \multicolumn{1}{|c|}{ Clay } & \multicolumn{1}{|c|}{ Exchange cations } & $\begin{array}{c}\mathbf{2 \theta} \\
{\left[{ }^{\circ} \mathbf{}\right.}\end{array}$ & $\begin{array}{c}\text { Basal } \\
\text { spacing } \\
{[\mathbf{n m}]}\end{array}$ \\
\hline Na-MMT & $\mathrm{Na}^{+}$ & 7.12 & 1.24 \\
\hline ODA-MMT & $\mathrm{CH}_{3}\left(\mathrm{CH}_{2}\right)_{17} \mathrm{NH}_{3}{ }^{+}$ & 3.12 & 2.83 \\
\hline DDOA-MMT & {$\left[\mathrm{CH}_{3}\left(\mathrm{CH}_{2}\right)_{17}\right]_{2} \mathrm{~N}_{\left(\mathrm{CH}_{3}\right)_{2}}{ }^{+}$} & 2.76 & 3.20 \\
\hline
\end{tabular}

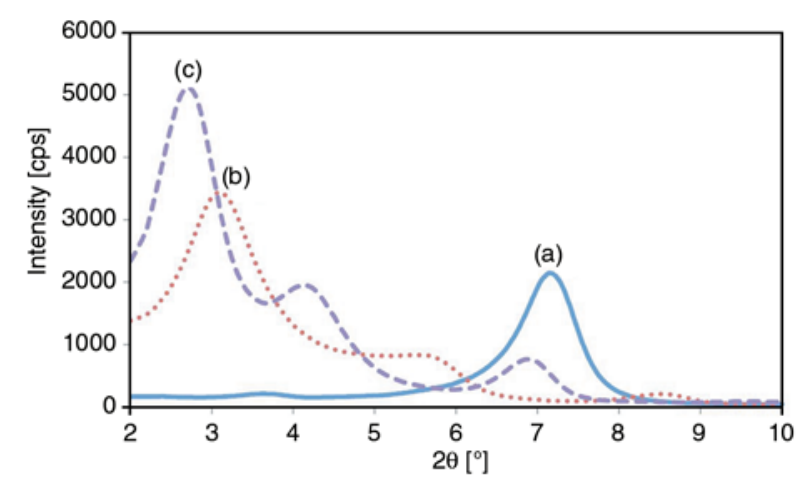

Figure 2. XRD patterns of (a) Na-MMT, (b) ODA-MMT and (c) DDOA-MMT 
There are three peaks observed for DDOA-MMT. The three spacings are attributed to the arrangement of the DDOA surfactant molecule in the clay layers and the presence of unmodified clay. The peak at $2 \theta=6.88^{\circ}(1.28 \mathrm{~nm})$ is a similar space to the Na-MMT, so this spacing is attributed to unmodified Na-MMT. The peak at $2 \theta=4.14^{\circ}(2.13 \mathrm{~nm})$ may be due to the molecular arrangement with the surfactant molecules laying flat to the surface, and peak at $2 \theta=2.76^{\circ}(3.20 \mathrm{~nm})$ is attributed to the surfactant molecules at $90^{\circ}$ to the surface [23].

On the other hand, ODA-MMT shows only two peaks in the XRD pattern [24]. The peak at $2 \theta=3.12^{\circ}(2.83 \mathrm{~nm})$ corresponds to the basal spacing of ODA-MMT. Another peak at $2 \theta=5.75^{\circ}$ $(1.54 \mathrm{~nm})$ attributed to the arrangement of surfactant molecules parallel to the surface of clay [23].

\subsection{Characterization of nanocomposites}

\subsubsection{X-ray diffraction analysis}

The nanostructure of layered silicate nanocomposites is established using XRD analysis at low angles $\left(2 \theta<10^{\circ}\right)$. Figure 3 shows the XRD pattern of Na-MMT and PBS/PBAT/Na-MMT composites at different clay loadings. Due to the hydrophilic nature of Na-MMT, it is hardly intercalated into the polymer blend. The basal spacing of composites with the clay loading of 1 and $3 \mathrm{wt} \%$ could not be detected, which may be due to low clay content or absence of any ordered layer structure. This lack of intergallery clay diffraction is due to the exfoliation and random distribution of the clay platelets within the polymer blend [25]. When 5 and $7 \mathrm{wt} \%$ of Na-MMT is added to the polymer blend, the diffraction angle of Na-MMT is shifted from $7.12^{\circ}$ $(1.24 \mathrm{~nm})$ to lower angle $6.48^{\circ}(1.36 \mathrm{~nm})$ and $6.58^{\circ}$ $(1.34 \mathrm{~nm})$ respectively. The intensity of the charac-

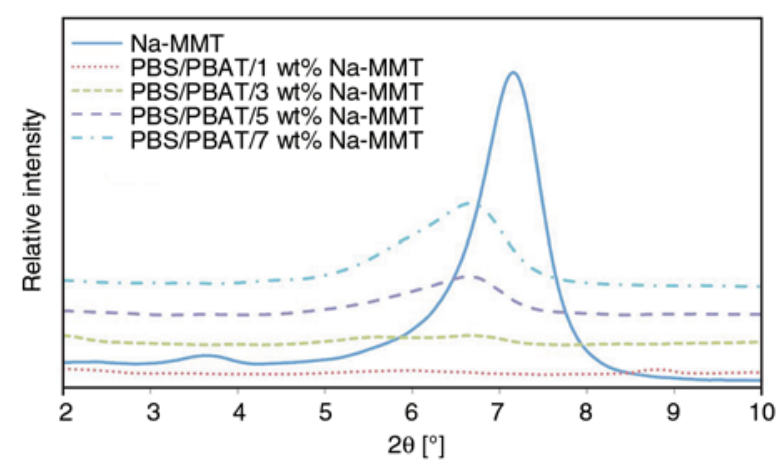

Figure 3. XRD patterns of Na-MMT and PBS/PBAT composites at different Na-MMT clay loadings

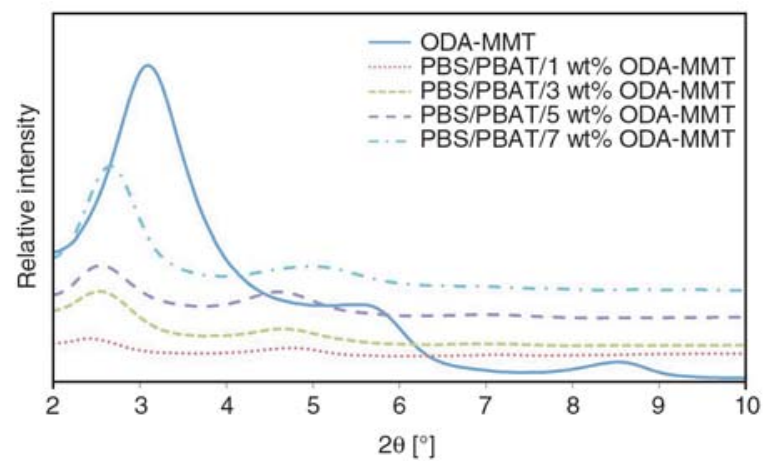

Figure 4. XRD patterns of ODA-MMT and PBS/PBAT composites at different ODA-MMT clay loadings

teristic peak of Na-MMT was reduced significantly, but almost retains its position, indicating the formation of a conventional or phase separated composites [26]. Such structure was expected since polymer matrices have no interaction with the highly hydrophilic Na-MMT surface.

The intercalation of the polymer chains would increase the interlayer spacing compared with that of clay, which would shift the peak towards a lower angle. Figure 4 shows the XRD pattern of ODAMMT and PBS/PBAT/ODA-MMT nanocomposites. ODA-MMT shows a characteristic peak at diffraction angle of $3.12^{\circ}$ corresponding to basal spacing $2.83 \mathrm{~nm}$. The increases in the basal spacing of ODA-MMT from 2.83 to $3.59,3.45,3.44$ and $3.31 \mathrm{~nm}$ when $1,3,5$ and $7 \mathrm{wt} \%$ of ODA-MMT respectively incorporated into $\mathrm{PBS} / \mathrm{PBAT}$, indicated that the polymer chain is successfully intercalated into the clay layers forming intercalated type nanocomposites.

Figure 5 shows the XRD pattern of DDOA-MMT and PBS/PBAT/DDOA-MMT composites. DDOAMMT shows a sharp peak at diffraction angle of $2.76^{\circ}$ corresponding to $3.20 \mathrm{~nm}$ of basal spacing.

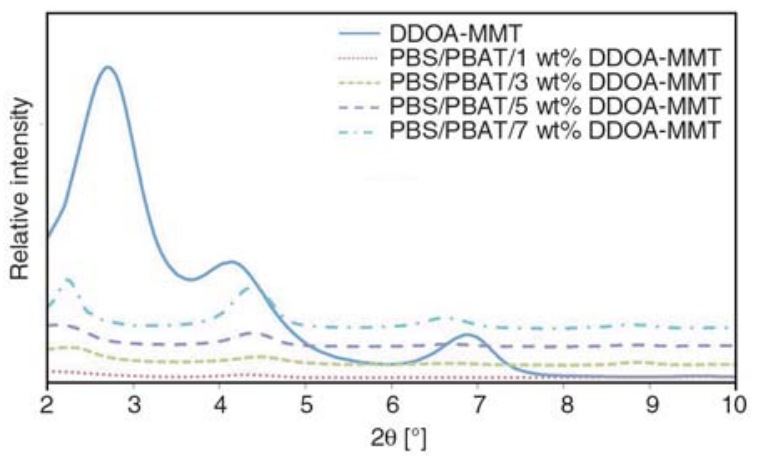

Figure 5. XRD patterns DDOA-MMT and PBS/PBAT composites at different DDOA-MMT clay loadings 
Table 3. Basal spacing of PBS/PBAT composites at various clay loadings

\begin{tabular}{|l|c|c|}
\hline \multicolumn{1}{|c|}{ Sample } & $\begin{array}{c}\mathbf{2} \boldsymbol{\theta} \\
{\left[{ }^{\circ}\right]}\end{array}$ & $\begin{array}{c}\text { Basal spacing } \\
{[\mathbf{n m}]}\end{array}$ \\
\hline Na-MMT & 7.12 & 1.24 \\
\hline PBS/PBAT/1 wt\% Na-MMT & - & - \\
\hline PBS/PBAT/3 wt\% Na-MMT & - & - \\
\hline PBS/PBAT/5 wt\% Na-MMT & 6.48 & 1.36 \\
\hline PBS/PBAT/7 wt\% Na-MMT & 6.58 & 1.34 \\
\hline ODA-MMT & 3.12 & 2.83 \\
\hline PBS/PBAT/1 wt\% ODA-MMT & 2.46 & 3.59 \\
\hline PBS/PBAT/3 wt\% ODA-MMT & 2.56 & 3.45 \\
\hline PBS/PBAT/5 wt\% ODA-MMT & 2.57 & 3.44 \\
\hline PBS/PBAT/7 wt\% ODA-MMT & 2.67 & 3.31 \\
\hline DDOA-MMT & 2.76 & 3.20 \\
\hline PBS/PBAT/1 wt\% DDOA-MMT & - & - \\
\hline PBS/PBAT/3 wt\% DDOA-MMT & 2.31 & 3.81 \\
\hline PBS/PBAT/5 wt\% DDOA-MMT & 2.28 & 3.88 \\
\hline PBS/PBAT/7 wt\% DDOA-MMT & 2.24 & 3.93 \\
\hline
\end{tabular}

The increases in the basal spacing of DDOA-MMT from 3.20 to $3.81,3.88$, and $3.93 \mathrm{~nm}$ when 3,5 and $7 \mathrm{wt} \%$ of DDOA-MMT respectively incorporated into PBS/PBAT, indicated that the polymer chain is successfully intercalated into the clay layers. The existence of sharp peaks shows that all the composites still retain an ordered structure. For the case of PBS/PBAT $/ 1$ wt $\%$, the characteristic peak of the original clay disappeared, indicating that the clay was fully exfoliated in the blend matrix. Thus, it could be said that it forming the exfoliated type of nanocomposite and will be confirmed by TEM. Basal spacing of all nanocomposites was summarized in Table 3.

\subsubsection{Transmission Electron Microscopy (TEM)}

The dispersion of layered silicates in the composites were observed by TEM as shown in the Figure 6, which presents PBS/PBAT composites with $1 \mathrm{wt} \%$ of (a) Na-MMT and (b) DDOA-MMT. The dark lines are the cross section of intercalated silicate layers and the bright areas are the matrix.

In PBS/PBAT/Na-MMT, the clay persists as tactoids of agglomerates throughout the polymer matrix as shown in Figure 6a. This incomplete dispersal of the reinforcing phase inhibits ideal surface contact between the polymer and clay, creating large regions of clay tactoids in the composite. This observation is in agreement with the XRD result which shows little shifting in the diffraction peak of
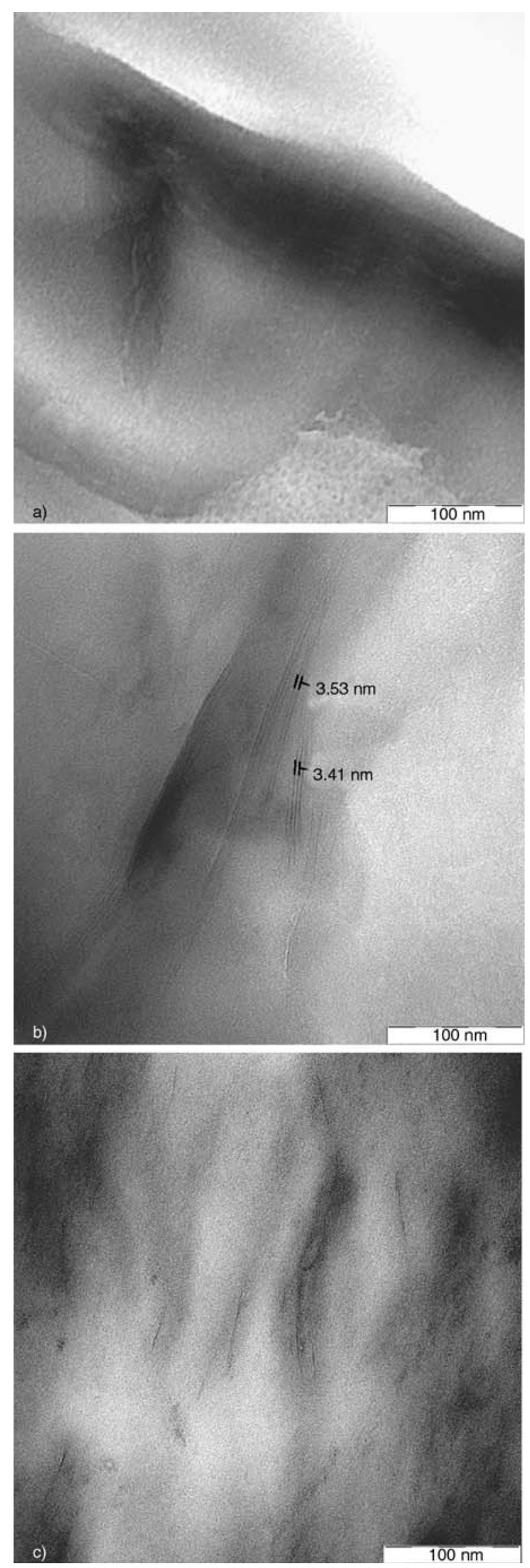

Figure 6. TEM images of PBS/PBAT composite with 1 wt $\%$ of (a) Na-MMT (b) ODA-MMT and (c) DDOA-MMT 
Na-MMT for PBS/PBAT/Na-MMT composites and formed as immiscible or phase separated microcomposites. PBS/PBAT/ODA-MMT (Figure 6b) shows that the layers of clay were disordered and the PBS/PBAT matrix was intercalated into the gallery of the clay. It is consistent with the XRD result shows that a large increase in basal spacing of the clay and formed intercalated type of nanocomposites.

On the other hand, TEM image of PBS/PBAT/ DDOA-MMT shown in Figure $6 \mathrm{c}$ demonstrate single silicate layers homogenously dispersed in the polymer matrix, indicates the formation of a fully exfoliated nanocomposite. This finding shows that DDOA-MMT exhibits better dispersion of clay layers in the PBS/PBAT matrix, and is in accordance with the XRD observation shown in Figure 5, supports the formation of an exfoliated type nanocomposite. Because of that, better homogeneity and tensile properties were achieved for the PBS/ PBAT/DDOA-MMT which will be proved by SEM and tensile tests.

\subsubsection{Tensile roperties}

The tensile properties of PBS/PBAT/Na-MMT and PBS/PBAT/OMMT composites at various contents of clays are shown in Figure 7 and Figure 8, respec-

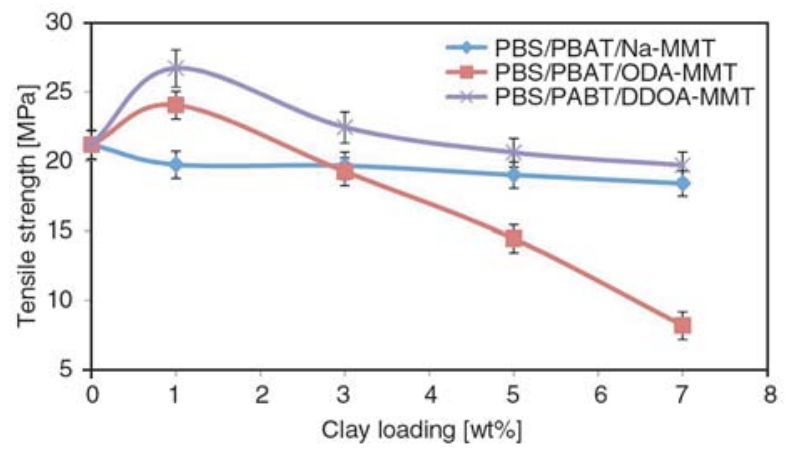

Figure 7. Tensile strength of PBS/PBAT composites

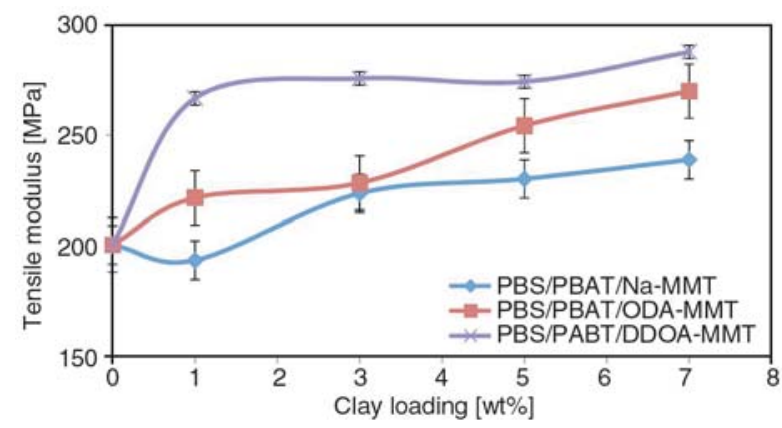

Figure 8. Tensile modulus of PBS/PBAT composites tively. The tensile strength of pristine PBS/PBAT blend is $21.20 \mathrm{MPa}$. Tensile strength of PBS/ PBAT/Na-MMT decreased as the clay content increases. This is due to the hydrophilic nature of Na-MMT which is incompatible with the hydrophobic polymer matrix. However, the reduction could also be attributed to poor dispersion and agglomeration of Na-MMT in the blends as shown in Figure $6 \mathrm{a}$.

It is clearly seen that the highest tensile strength was achieved at $1 \mathrm{wt} \%$ of OMMT clay loading. This suggests that OMMT acts as reinforcing filler, which increases interaction at the phase boundaries upon the addition of OMMT. Strong interphase interaction between the matrix and the dispersed phase is believed reduce the stress concentration point when tensile load is applied. The OMMT is able to act as reinforcing filler due to its high aspect ratio and platelet structure. However, when the amount of clay is above $1 \mathrm{wt} \%$, only a part of the clay locates in the interfacial area, and the excess is dispersed in the matrix affecting its homogeneity and consequently the tensile strength of the blends $[27,28]$. Some of the clay is present in the form tactoids, remained partially intercalated and stacked, which weakened the reinforcing effect [29]. Thus, the reinforcing effect is reduced for nanocomposites with higher clay loading owing to poor dispersion of clay and hence unable to transfer stress efficiently. When comparing the OMMT as filler for PBS/PBAT blend, it is observed that at $1 \mathrm{wt} \%$ clay loading the reinforcing effect of DDOA-MMT is more noticeable.

Incorporation of clay into PBS/PBAT blend also increases the tensile modulus [30]. Clay has been found to be efficient in stiffening polymers [31]. The tensile modulus of PBS/PBAT/ODA-MMT increased up to $269.9 \mathrm{MPa}$, whereas the tensile modulus of PBS/PBAT/DDOA-MMT increased up to $287.7 \mathrm{MPa}$. The increase in tensile modulus is mainly due to the high aspect ratio and rigidity of clay layers. However, the tensile modulus increase in PBS/PBAT/OMMT is higher than PBS/PBAT/ Na-MMT at all clay loadings. This indicates that OMMT is more compatible with polymer blend compared to Na-MMT, and hence increase the stiffness of the nanocomposites. Once again the OMMT act as reinforcing filler better than the unmodified clay, Na-MMT. The enhancement of tensile modulus was reasonably ascribed to the 
constraint of the polymer chains by their interaction with the clay surfaces [32].

\subsubsection{Thermogravimetric Analysis (TGA)}

Generally, introduction of clay into polymeric matrices can improve their thermal stabilities since the clay can hinder the permeability of volatile degradation products out of the materials. The dispersed clay generates a barrier which delays the release of thermal degradation products in comparison the pristine polymer [22]. Figures 9 and 10 show the TG and DTG thermograms respectively of PBS/PBAT blend and PBS/PBAT composites. The weight loss of the blend and nanocomposites due to degradation is monitored as a function of temperature. The characteristic thermal parameters selected were onset temperature, which is the initial weight loss temperature, and maximum degradation temperature, which is the highest thermal degradation rate temperature. The results are summarized in the Table 4.

The PBS/PBAT blend shows the onset temperature of $215.3^{\circ} \mathrm{C}$, which increased to $223.6,237.5$ and $234.0^{\circ} \mathrm{C}$ when Na-MMT, ODA-MMT and DDOA-

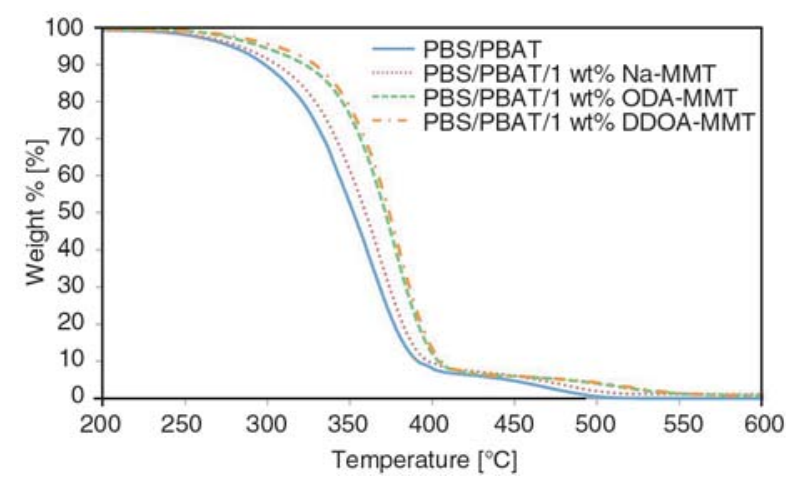

Figure 9. TG thermograms of PBS/PBAT and PBS/PBAT composites

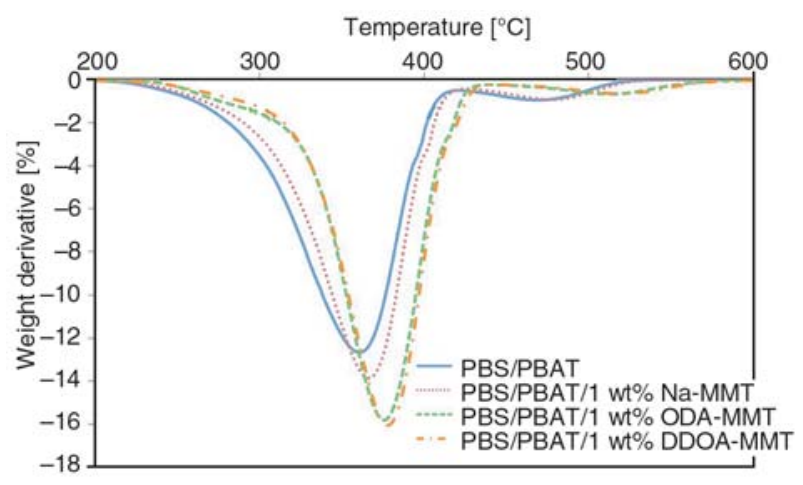

Figure 10. DTG thermograms of PBS/PBAT and PBS/PBAT composites
Table 4. TG results of PBS/PBAT and PBS/PBAT composites

\begin{tabular}{|l|c|c|}
\hline \multicolumn{1}{|c|}{ Sample } & $\begin{array}{c}\text { Onset } \\
\text { temperature } \\
{\left[{ }^{\circ} \mathbf{C}\right]}\end{array}$ & $\begin{array}{c}\text { Maximum } \\
\text { degradation } \\
\text { temperature } \\
\mathbf{T}_{\max }\left[{ }^{\circ} \mathbf{C}\right]\end{array}$ \\
\hline PBS/PBAT & 215.3 & 360.4 \\
\hline PBS/PBAT/Na-MMT & 223.6 & 366.6 \\
\hline PBS/PBAT/ODA-MMT & 237.5 & 375.4 \\
\hline PBS/PBAT/DDOA-MMT & 234.0 & 377.0 \\
\hline
\end{tabular}

MMT clays respectively incorporated into the blend. The incorporation of clay into polymer matrix was found to enhance the thermal stability. The improved thermal stability attributed to an ablative reassembling of the silicate layers which may occur on the surface of the nanocomposites creating a physical protective barrier on the surface of the material which hinder the diffusion of volatiles and assist the formation of char after decomposition [33]. However, the OMMT gave higher thermal stability compared to the hydrophilic Na-MMT indicating better interaction between PBS/PBAT matrix and OMMT. The maximum degradation temperature $\left(T_{\max }\right)$ also increased by compounding the PBS/PBAT with OMMT.

\subsubsection{Scanning Electron Microscopy (SEM)}

The fracture surface of the nanocomposites was examined by scanning electron microscope to study the morphology of the surface. Figure 11 shows SEM micrographs of fractured surface of PBS/ PBAT blend and its nanocomposites at magnification of $1000 \times$.

According to Jacob et al. [8], if the blend components have different melt viscosities, the morphology of the resulting blend will show the finely dispersed phase of the component with lower viscosity. Higher viscosity will lead to coarse dispersion of phases in a spherical domain. However in the case of blends containing higher concentrations of PBS, a reversal of the continuous phase was visible. Thus for PBS/PBAT blend, the PBAT with higher viscosity formed the continuous phase as shown by red arrows in the Figure 11a. This can further confirmed by etching the PBS/PBAT blend with dimethylformamide (DMF). PBS is soluble in DMF, while PBAT is insoluble. The DMF was used to dissolve the soluble phase. Figure 12 represents the micrograph of the PBS/PBAT blend after 


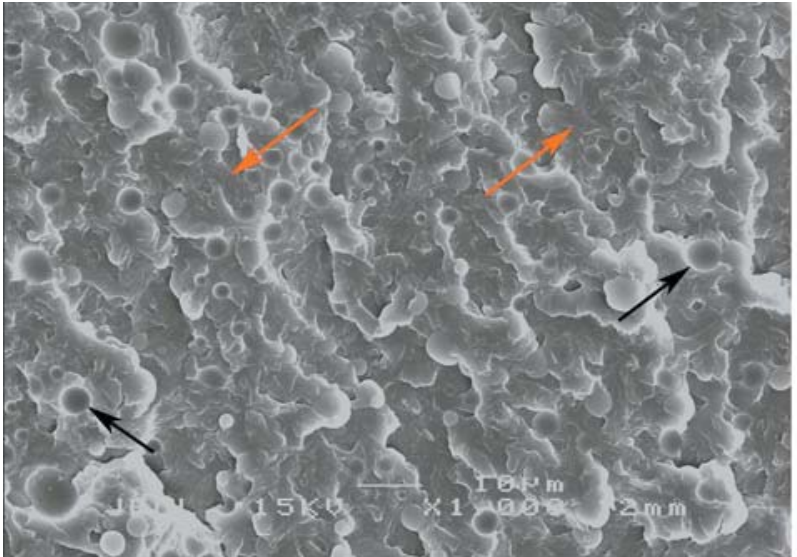

a)

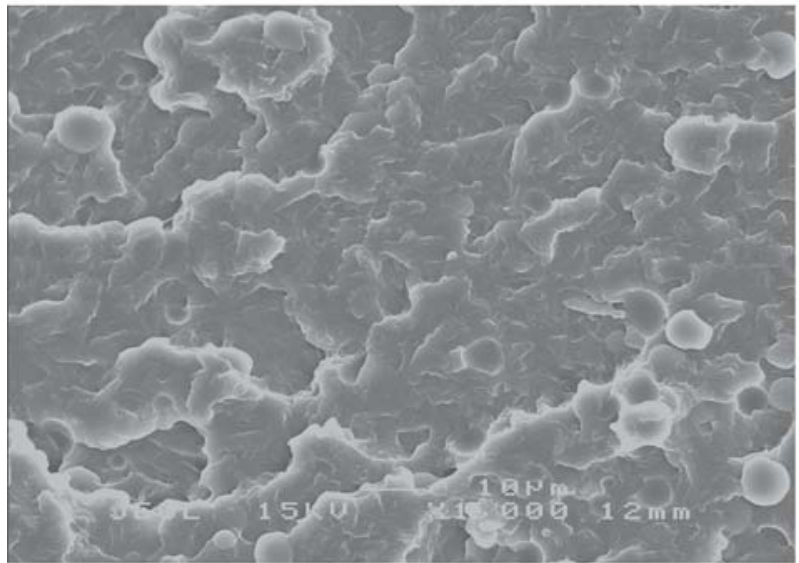

c)

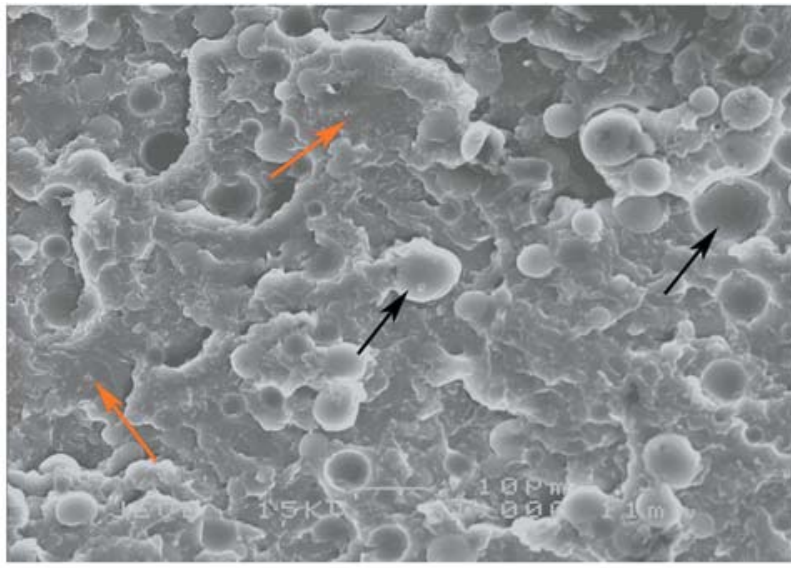

b)

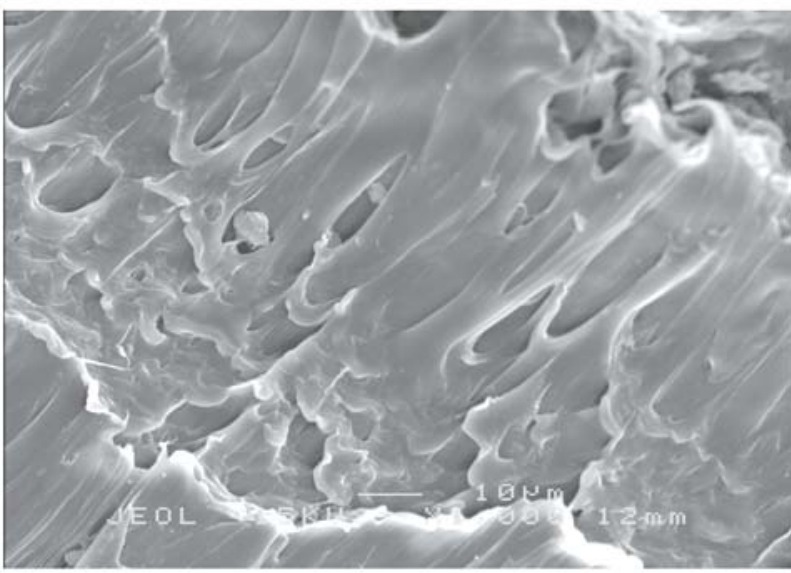

Figure 11. SEM images of (a) PBS/PBAT, and PBS/PBAT composite with 1 wt\% of (b) Na-MMT, (c) ODA-MMT and (d) DDOA-MMT

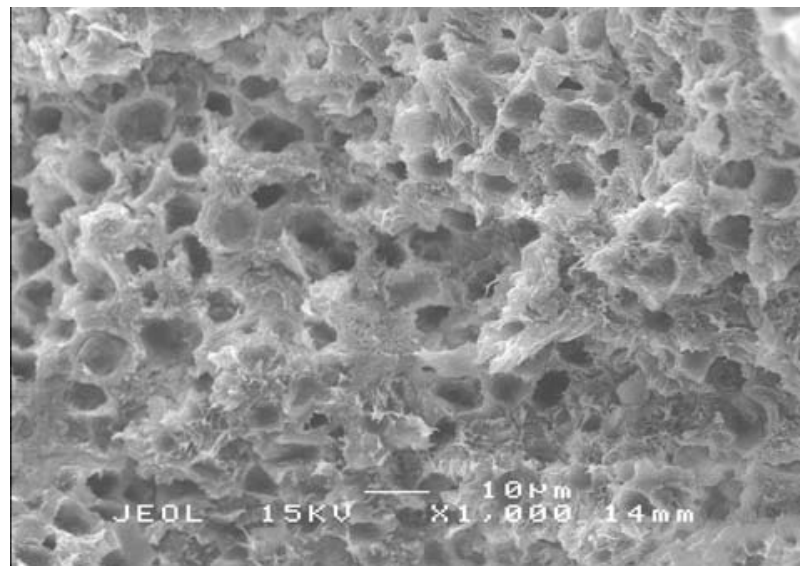

Figure 12. SEM micrograph of PBS/PBAT blend after etching with DMF

etching with DMF. The micrograph clearly showed that the PBS phase dissolved in the DMF and PBAT phase stayed intact during the etching process. However, PBS/PBAT nanocomposites dissolved in DMF solvent during the same etching process. This means that the PBS/PBAT blend was a miscible blend after incorporation of OMMT.
This finding reveals that OMMT can improve the miscibility of the blend.

When OMMT was incorporated into PBS/PBAT, there is a reduction of the domain size of the dispersed phase (PBS) as shown by black arrows which is related to a reduction of the coalescence rate of the dispersed phase and a compatibilizing effect of the OMMT at the interface between the two phases as shown in Figure $11 \mathrm{c}$ and $11 \mathrm{~d}$. Conversely, there often appears to be an increase in the dispersed phase domain size when OMMT is located in the dispersed phase $[9,34]$. So, the OMMT is located in the PBAT continuous phase in this PBS/PBAT blend system. According to Martins et al. [35], when the OMMT platelets are located in the continuous phase instead of the dispersed phase would lead to higher stiffness and this is in agreement with the tensile modulus results.

Some small void could be observed in PBS/PBAT/ Na-MMT (Figure 11b) compared to pristine PBS/ PBAT which indicates that the incompatibility of 
Na-MMT with the PBS/PBAT matrix. The presence of OMMT influences the morphological structural changes of the blend. As shown in Figure 11c and $11 \mathrm{~d}$, the PBS/PBAT phases have affinities to make nanolevel incorporation with OMMT. It indicates a good degree of mixing between the polymer phases with addition of OMMT, since this composite totally dissolved in DMF after addition of OMMT. As a result, the nanocomposite showed more homogeneous and single phase morphology compared to unmodified clay. In other word, the OMMT induces miscibility between PBS and PBAT.

\section{Conclusions}

OMMTs were successfully prepared from Na-MMT via cation exchange method by using octadecylammonium and dimethyldioctadecylammonium cation as surfactant. Intercalated and exfoliated types of PBS/PBAT/OMMT nanocomposites were successfully prepared by melt blending as proven by XRD and TEM. The tensile strength of PBS/PBAT/ OMMT nanocomposites was improved by reinforcing effects of OMMT and gives the maximum value at $1 \mathrm{wt} \%$ OMMT loading. Thermal stability was enhanced by incorporation of clay into PBS/ PBAT matrices, particularly OMMT. SEM micrographs showed that presence of OMMT in the PBS/PBAT blend improved the morphology of the compound. SEM micrographs also supported the finding of compatibility for the PBS/PBAT blend with OMMT through the homogeneous distribution which gives an improvement in mechanical properties.

\section{References}

[1] Fujimaki T.: Processability and properties of aliphatic polyesters, 'BIONOLLE', synthesized by polycondensation reaction. Polymer Degradation and Stability, 59, 209-214 (1998). DOI: $10.1016 / \mathrm{S} 0141-3910(97) 00220-6$

[2] Shih Y., Wang T., Jeng R., Wu J., Teng C.: Biodegradable nanocomposites based on poly(butylene succinate)/organoclay. Journal of Polymers and the Environment, 15, 151-158 (2007).

DOI: $10.1007 / \mathrm{s} 10924-007-0055-6$

[3] Chen G-X., Kim H-S., Kim E-S., Yoon J-S.: Compatibilization-like effect of reactive organoclay on the poly(l-lactide)/poly(butylene succinate) blends. Polymer, 46, 11829-11836 (2005).

DOI: $10.1016 /$ j.polymer.2005.10.056
[4] Okamoto K., Ray S. S., Okamoto M.: New poly(butylene succinate)/layered silicate nanocomposites. II. Effect of organically modified layered silicates on structure, properties, melt rheology, and biodegradability. Journal of Polymer Science Part B: Polymer Physics, 41, 3160-3172 (2003).

DOI: $10.1002 /$ polb.10708

[5] Chen G-X., Kim E-S., Yoon J-S.: Poly(butylene succinate)/twice functionalized organoclay nanocomposites: Preparation, characterization, and properties. Journal of Applied Polymer Science, 98, 1727-1732 (2005).

DOI: 10.1002/app.22264

[6] Someya Y., Nakazato T., Teramoto N., Shibata M.: Thermal and mechanical properties of poly(butylene succinate) nanocomposites with various organo-modified montmorillonites. Journal of Applied Polymer Science, 91, 1463-1475 (2004). DOI: $10.1002 / a p p .13366$

[7] Yu L., Dean K., Li L.: Polymer blends and composites from renewable resources. Progress in Polymer Science, 31, 576-602 (2006).

DOI: 10.1016/j.progpolymsci.2006.03.002

[8] Jacob J., Ramaswamy M., Mrinal B.: Evaluation of compatibility and properties of biodegradable polyester blends. Journal of Polymer Science Part A: Polymer Chemistry, 40, 2003-2014 (2002).

DOI: $10.1002 /$ pola.10297

[9] Khatua B. B., Lee D. J., Kim H. Y., Kim J. K.: Effect of organoclay platelets on morphology of nylon- 6 and poly(ethylene-ran-propylene) rubber blends. Macromolecules, 37, 2454-2459 (2004).

DOI: $\underline{10.1021 / \mathrm{ma} 0352072}$

[10] Voulgaris D., Petridis D.: Emulsifying effect of dimethyldioctadecylammonium-hectorite in polystyrene/poly(ethyl methacrylate) blends. Polymer, 43, 2213-2218 (2002).

DOI: $\underline{10.1016 / \mathrm{S} 0032-3861(02) 00039-3}$

[11] Sinha Ray S., Pouliot S., Bousmina M., Utracki L. A.: Role of organically modified layered silicate as an active interfacial modifier in immiscible polystyrene/ polypropylene blends. Polymer, 45, 8403-8413 (2004). DOI: 10.1016/j.polymer.2004.10.009

[12] Si M., Araki T., Ade H., Kilcoyne A. L. D., Fisher R., Sokolov J. C., Rafailovich M. H.: Compatibilizing bulk polymer blends by using organoclays. Macromolecules, 39, 4793-4801 (2006). DOI: $\underline{10.1021 / \mathrm{ma} 060125+}$

[13] Hong J. S., Namkung H., Ahn K. H., Lee S. J., Kim C.: The role of organically modified layered silicate in the breakup and coalescence of droplets in PBT/PE blends. Polymer, 47, 3967-3975 (2006). DOI: 10.1016/j.polymer.2006.03.077

[14] Su Q., Feng M., Zhang S., Jiang J., Yang M.: Melt blending of polypropylene-blend-polyamide 6-blendorganoclay systems. Polymer International, 56, 50-56 (2007).

DOI: $\underline{10.1002 / p i .2109}$ 
[15] Gelfer M. Y., Song H. H., Liu L., Hsiao B. S., Chu B., Rafailovich M., Si M., Zaitsev V.: Effects of organoclays on morphology and thermal and rheological properties of polystyrene and poly(methyl methacrylate) blends. Journal of Polymer Science Part B: Polymer Physics, 41, 44-54 (2003).

DOI: $10.1002 /$ polb. 10360

[16] Sinha Ray S., Okamoto M.: Polymer/layered silicate nanocomposites: A review from preparation to processing. Progress in Polymer Science, 28, 1539-1641 (2003).

DOI: $10.1016 / j . p r o g p o l y m s c i .2003 .08 .002$

[17] Giannelis E. P.: Polymer layered silicate nanocomposites. Advanced Materials, 8, 29-35 (1996). DOI: $10.1002 / \mathrm{adma} .19960080104$

[18] Sharif J., Wan Yunus W. M. Z., Khairul Z. H. M. D., Mansor H. A.: Preparation and properties of radiation crosslinked natural rubber/clay nanocomposites. Polymer Testing, 24, 211-217 (2005).

DOI: $10.1016 /$ j.polymertesting.2004.08.008

[19] Bala P., Samantaraya B. K., Srivastava S. K.: Synthesis and characterization of Na-montmorillonite-alkylammonium intercalation compounds. Materials Research Bulletin, 35, 1717-1724 (2000). DOI: $10.1016 / \mathrm{S} 0025-5408(00) 00368-8$

[20] Xue W., He H., Zhu J., Yuan P.: FTIR investigation of CTAB-Al-montmorillonite complexes. Spectrochimica Acta Part A: Molecular and Biomolecular Spectroscopy, 67, 1030-1036 (2007). DOI: $\underline{10.1016 / j . s a a .2006 .09 .024}$

[21] Xi Y., Frost R. L., He H.: Modification of the surfaces of Wyoming montmorillonite by the cationic surfactants alkyl trimethyl, dialkyl dimethyl, and trialkyl methyl ammonium bromides. Journal of Colloid and Interface Science, 305, 150-158 (2007).

DOI: $10.1016 /$ j.jcis.2006.09.033

[22] Agag T., Koga T., Takeichi T.: Studies on thermal and mechanical properties of polyimide-clay nanocomposites. Polymer, 42, 3399-3408 (2001).

DOI: 10.1016/S0032-3861(00)00824-7

[23] Zhou Q., Frost R. L., He H., Xi Y., Zbik M.: TEM, $\mathrm{XRD}$, and thermal stability of adsorbed paranitrophenol on DDOAB organoclay. Journal of Colloid and Interface Science, 311, 24-37 (2007).

DOI: $\underline{10.1016 / \text { j.jcis.2007.02.039 }}$

[24] Someya Y., Sugahara Y., Shibata M.: Nanocomposites based on poly(butylene adipate-co-terephthalate) and montmorillonite. Journal of Applied Polymer Science, 95, 386-392 (2005).

DOI: $10.1002 /$ app. 21333

[25] Wu Z., Zhou C., Qi R., Zhang H.: Synthesis and characterization of nylon 1012/clay nanocomposite. Journal of Applied Polymer Science, 83, 2403-2410 (2002).

DOI: $10.1002 /$ app. 10198
[26] Paul D. R., Robeson L. M.: Polymer nanotechnology: Nanocomposites. Polymer, 49, 3187-3204 (2008). DOI: 10.1016/j.polymer.2008.04.017

[27] Sathe S. N., Devi S., Srinivasa Rao G. S., Rao K. V.: Relationship between morphology and mechanical properties of binary and compatibilized ternary blends of polypropylene and nylon 6. Journal of Applied Polymer Science, 61, 97-107 (1996).

DOI: $10.1002 /($ SICI $) 1097-4628(19960705) 61: 1<97::$ AID-APP11>3.0.CO;2-X

[28] Sathe S. N., Srinivasa Rao G. S., Rao K. V., Devi S.: The effect of composition on morphological, thermal, and mechanical properties of polypropylene/nylon6/polypropylene-g-butyl acrylate blends. Polymer Engineering and Science, 36, 2443-2450 (1996). DOI: $10.1002 /$ pen.10642

[29] Ferrigno T. H.: Principles of filler selection and use. in 'Handbooks of fillers for plastic' (eds.: H. S. Kartz, J. V. Milewski) Van Nostrand Reinhold, New York, 6-81 (1987).

[30] Reichert P., Nitz H., Klinke S., Brandsch R., Thomann R., Mühaupt R.: Poly(propylene)/organoclay nanocomposite formation: Influence of compatibilizer functionality and organoclay modification. Macromolecular Materials and Engineering, 275, 8-17 (2000).

DOI: $10.1002 /($ SICI $) 1439-2054(20000201) 275: 1<8:$ : AID-MAME8>3.0.CO;2-6

[31] Wang J., Pyrz R.: Prediction of the overall moduli of layered silicate-reinforced nanocomposites- Part I: Basic theory and formulas. Composites Science and Technology, 64, 925-934 (2004).

DOI: $10.1016 / \mathrm{S} 0266-3538(03) 00024-1$

[32] Shelley J. S., Mather P. T., DeVries K. L.: Reinforcement and environmental degradation of nylon-6/clay nanocomposites. Polymer, 42, 5849-5858 (2001). DOI: $10.1016 / \mathrm{S} 0032-3861(00) 00900-9$

[33] Gilman J. W., Jackson C. L., Morgan A. B., Harris R., Manias E., Giannelis E. P., Wuthenow M., Hilton D., Phillips S. H.: Flammability properties of polymerlayered-silicate nanocomposites. Polypropylene and polystyrene nanocomposites. Chemistry of Materials, 12, 1866-1873 (2000).

DOI: $\underline{10.1021 / \mathrm{cm} 0001760}$

[34] Kontopoulou M., Liu Y., Austin J. R., Parent J. S.: The dynamics of montmorillonite clay dispersion and morphology development in immiscible ethylenepropylene rubber/polypropylene blends. Polymer, 48, 4520-4528 (2007).

DOI: $10.1016 /$ j.polymer.2007.05.068

[35] Martins C. G., Larocca N. M., Paul D. R., Pessan L. A.: Nanocomposites formed from polypropylene/ EVA blends. Polymer, 50, 1743-1754 (2009). DOI: 10.1016/j.polymer.2009.01.059 